\title{
Reduction of shrinkage porosities in aluminum alloy castings by external pressure fluctuation under gravity field
}

\author{
*Shi-ping Wu', Ru-jia Wang', Ye Wang ${ }^{1,2}$, Wei Chen', and Ze-sheng Ji $^{\mathbf{2}}$ \\ 1. School of Materials Science and Engineering, Harbin Institute of Technology, Harbin 150001, China \\ 2. School of Materials Science and Engineering, Harbin University of Science and Technology, Harbin 150001, China
}

\begin{abstract}
A novel method to improve the feeding capacity of ZL205A alloy castings by pressure fluctuation during its solidification process under gravity field was proposed. The experiments were done in the graphite mould by applying the fluctuation pressure at the top of the riser. Results of the X-ray inspection of castings and simulations of flow velocity of alloy melt and temperature field show that the new method can effectively improve the feeding capacity and significantly reduce the shrinkage in the castings. The mechanism of improving the feeding capacity by pressure fluctuation is that the fluctuating pressure can make the ZL205A alloy melt form a vibration wave in the melt. The vibration wave can intensify the convection of the melt, and therefore, break down the barrage from the feeding channel which forms during the solidification process of the ZL205A alloy, improving the feeding capacity.
\end{abstract}

Key words: Fluctuation pressure; shrinkage porosity; ZL205A alloy; gravity casting
CLC numbers: TG146.21
Document code: A
Article ID: 1672-6421(2018 05-372-06

\begin{abstract}
Chrinkage porosity is one of the typical and most common defects in castings, which can deteriorate the properties of produced castings. It is very difficult to reduce the defects through subsequent thermomechanical treatments ${ }^{[1]}$ or forging process ${ }^{[2]}$, especially for defects formed in the near-net shape casting process. A lot of research has been done to extend the service life of castings by reducing the shrinkage porosity in the castings ${ }^{[3-8]}$. Generally, this kind of defects are caused by insufficient feeding pressure or obstruction of the feeding channel ${ }^{[9-12]}$.

The studies of many investigators show that vibration can improve the casting quality since Chernov first successfully refined grains of steel castings by gentle vibration of the mould. The application of vibration to the mould is one of the most convenient methods to improve casting quality ${ }^{[13]}$. However, there still are some drawbacks, and one example is that vibration with low frequency during the solidification process usually makes
\end{abstract}

\footnotetext{
* Shi-ping $\mathrm{Wu}$
}

Male, Ph.D., Prof. Research interests: aluminum melt treatment technology, materials forming technology, solidification simulation.

E-mail: spwu@hit.edu.cn

Received: 2017-12-14; Accepted: 2018-04-15 the liquid melt release heat from the mould through the sprue ${ }^{[14]}$. Therefore, direct vibrations on the liquid melt by ultrasonic ${ }^{[15]}$, vibration injection molding ${ }^{[16]}$ or electromagnetism ${ }^{[17,18]}$ were used to improve the quality of castings.

It is worthwhile to notice that all the above vibration methods improving the casting quality through grain refinement for dendritically solidifying materials are based on the dendrite fragmentation mechanism, particularly at high-frequency. For ZL205A alloy, which has been widely used in aviation, aerospace and military industries ${ }^{[19-22]}$, the dendrite fragmentation mechanism did not appear effective, many shrinkage porosities would occur after solidification, which cannot be avoided even by a low pressure die casting process.

Therefore, a new method was proposed in the present work after studying the feeding mechanism of "burst feeding" through the vibration to improve the feeding capacity, in which the vibration is produced by fluctuation pressure through compressing and releasing nitrogen gas, which can induce the "burst feeding" process ${ }^{[23]}$. This approach can not only prevent the contamination of the transducer component, but also overcome the low transmission efficiency shortcoming of mechanical vibration. 


\section{Experimental procedure}

ZL205A alloy was selected as the casting material, and graphite was selected as the mold material. The experiment was done in the gravity field in order to achieve the solidification under the fluctuation pressure. The geometry structure and size of the casting mould is shown in Fig.1(a). Part A is a riser; Part B is an investigation area of shrinkage porosity; Part $\mathrm{C}$ is set for removing the casting easily. The graphite mold was directly placed in a resistance furnace with a crucible, where the ZL205A alloy was melted. After the ZL205A alloy melt was kept at 700 ${ }^{\circ} \mathrm{C}$ for $10 \mathrm{~min}$, it was put into the self-developed fluctuation

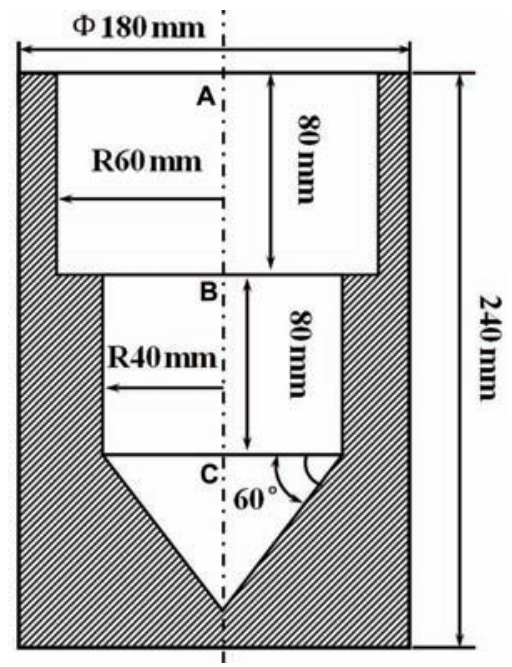

(a) Geometry of casting mould pressure experiment device as shown in Fig. 1(b). The heatresistant sealing material was used to ensure the gas tightness between the graphite mould and the top cover. The pressure was provided by a high-pressure nitrogen gas bottle tank. The fluctuation pressure was regulated by the exhaust valve, while the exhaust valve controlled the pressure sensor. The exhaust valve would be opened when the pressure reached the preset pressure, and it would be closed when the pressure dropped to lower than the preset one. The fluctuation pressure would be formed by opening and closing the exhaust valve several times. The casting mould was fixed on a large metal plate to prevent the shake of the mould caused by different pressures.

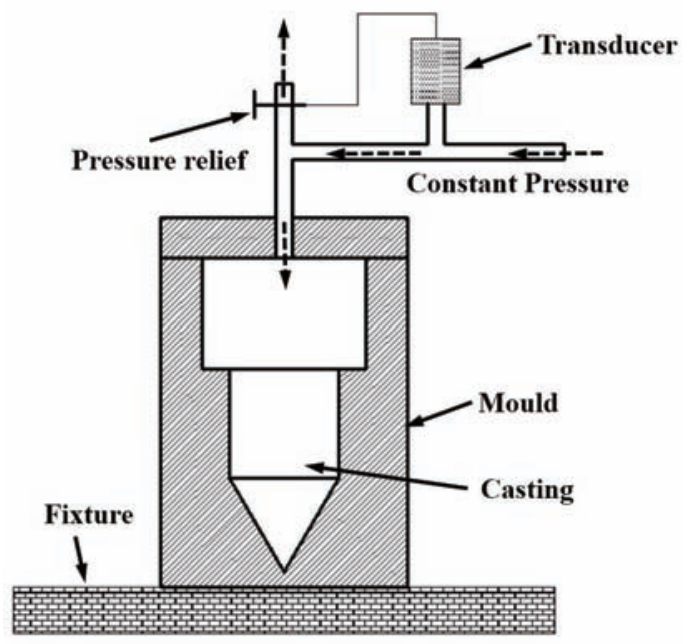

(b) Fluctuation pressure device

Fig. 1: Schematic of fluctuation pressure experiment device

The molten ZL205A alloy solidified in the gravity field with fluctuation pressure ranging from $0.1 \mathrm{MPa}$ to $0.2 \mathrm{MPa}$, where $0.1 \mathrm{MPa}$ represents connecting to the atmosphere without additional pressure; $0.2 \mathrm{MPa}$ represents the additional pressure of applied 0.1 MPa. The fluctuation pressure applied in the first two minutes of the present experiment is shown in Fig. 2. The fluctuation frequency was $0.25 \mathrm{~Hz}$, and the fluctuation amplitude

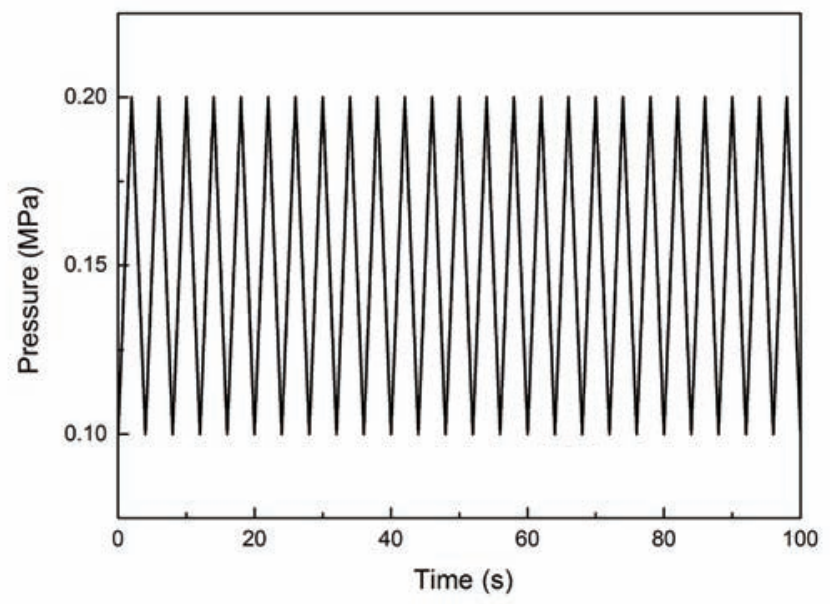

Fig. 2: Pressure curve of fluctuation pressure experiment was $0.1 \mathrm{MPa}$.

In order to study the effect of pressure fluctuation on the feeding capacity under the gravity field, the experimental scheme presented in Table 1 was designed. The alloy in scheme \#1 solidified under the gravity field with constant pressure of 0.1 $\mathrm{MPa}$. The alloy in scheme \#2 solidified under the gravity field with a constant pressure to study the effect of absolute pressure on the feeding capacity. The alloy in scheme \#3 solidified under the gravity field with the fluctuation pressure to study the impact of fluctuation pressure on the feeding capacity. The effect of the fluctuation pressure can finally be obtained by the comparison of the three schemes. For the convenience of comparison, the experimental conditions for the three schemes were exactly the same in temperature control, along with the pressure differences.

Table 1: Experimental conditions

$\begin{array}{lccc} & \# 1 & \text { \#2 } & \text { \#3 } \\ \text { Gravity } & \mathrm{Y} & \mathrm{Y} & \mathrm{Y} \\ \text { Pressure } & \mathrm{Y}(0.1 \mathrm{MPa}) & \mathrm{Y}(0.2 \mathrm{MPa}) & \mathrm{Y}(0.1-0.2 \mathrm{MPa}) \\ \text { Fluctuation } & \mathrm{N} & \mathrm{N} & \mathrm{Y}(f=0.25 \mathrm{~Hz})\end{array}$




\section{Results and discussion}

The finished castings are shown in Fig. 3. Non-destructive $\mathrm{X}$-ray detection was carried out to detect the shrinkage

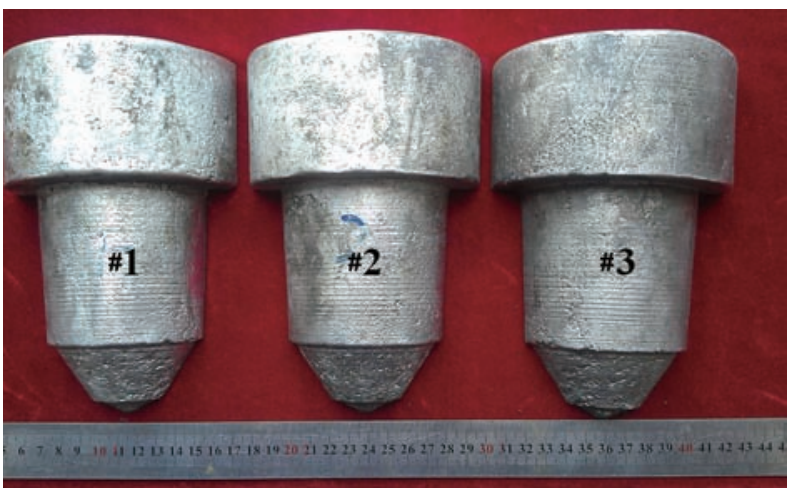

Constant pressure of $0.1 \mathrm{MPa}(\# 1)$, constant pressure of 0.2 MPa (\#2), fluctuation pressure (\#3)

Fig. 3: Finished castings solidified under different conditions

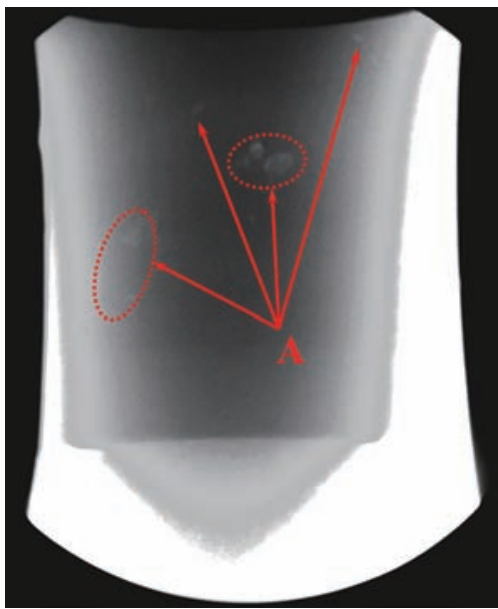

(a) Constant pressure of $0.1 \mathrm{MPa}(\# 1)$

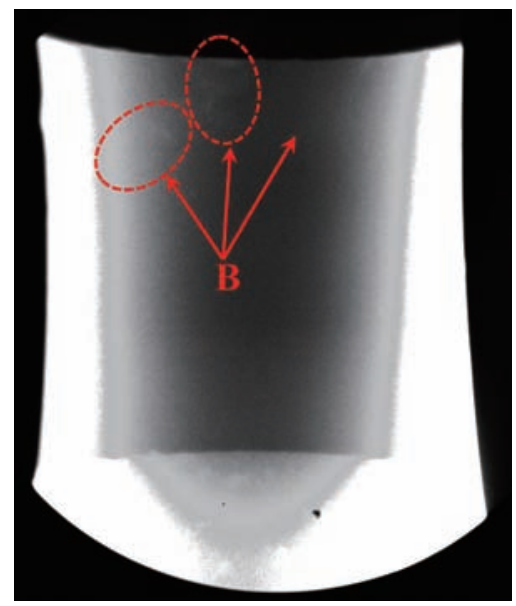

(b) Constant pressure of $0.2 \mathrm{MPa}(\# 2)$ porosity in the castings and the results are shown in Fig. 4.

The shrinkage defects in the castings were characterized by the area of shrinkage porosity. As shown in Fig. 4 and Table 2, there are shrinkage porosity marked A and B in Fig. 4 in casting \#1 and casting \#2, and the shrinkage porosity area of casting \#2 is smaller than that of casting \#1. These results can reflect the feeding ability of the castings.

Table 2: Shrinkage porosity area of finished castings

\begin{tabular}{lccc} 
& \multicolumn{4}{c}{ Casting No. } \\
& \#1 & \#2 & \#3 \\
Shrinkage porosity area $\left(\mathrm{mm}^{2}\right)$ & 166.61 & 132.94 & 0
\end{tabular}

The analysis results indicated that the shrinkage porosity area of the finished casting solidified under constant pressure is smaller than that solidified under the gravity field with no additional pressure. The solidified castings under pressure fluctuation without shrinkage porosity defect were obtained. The highly improved feeding capacity in the work demonstrated that the feeding ability improvement through

Fig. 4: X-ray detection results of finished castings

pressure fluctuation was feasible. The reason is that the fluctuation pressure exerted on the surface of the alloy melt is like a vibration boundary condition applied to the casting (Fig. 5), while both the melt and the solidified alloy can transmit pressure, therefore, the applied vibration can inevitably transmit in the solidification system. Therefore, the effect of fluctuation pressure can be regarded as the influence of vibration on the feeding ability.

Vibration can reinforce the convection in the melt during the alloy solidification ${ }^{[24]}$. This can be verified by the numerical simulation results by the software ProCAST, as shown in Fig. 6.

The numerical results show that the pressure fluctuation could promote the increase of flow velocity during the alloy solidification. According to Darcy's law, the flow velocity improvement of alloy melt would definitely increase the feeding ability of castings. The experimental results obtained in the study were inferred to be more unambiguous and believable.

The solidification processes in Fig.7 show that the castings without

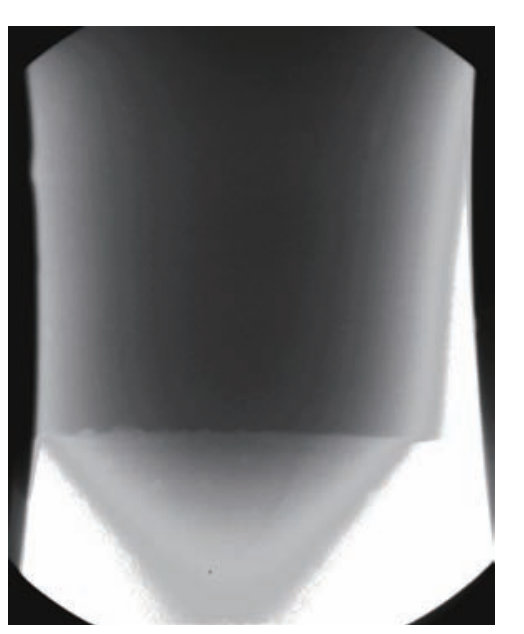

(c) Fluctuation pressure(\#3) 
(a)

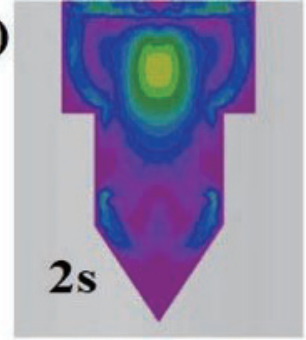

(b)

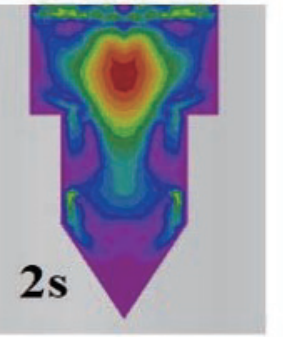

(c)

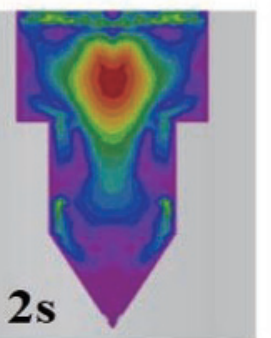

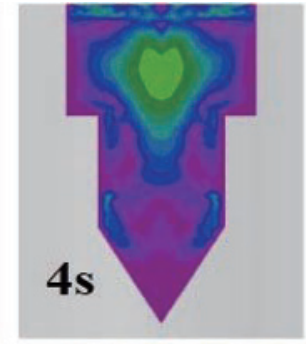
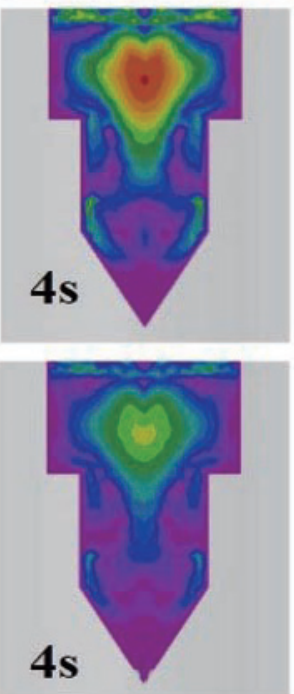

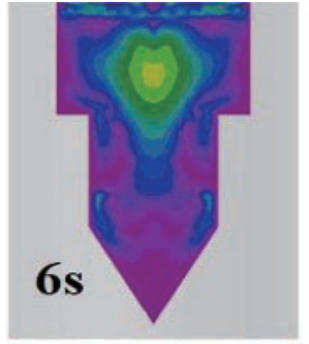

Fluid Velocity-Magnitude $\left(\mathrm{m} \cdot \mathrm{s}^{-1}\right)$
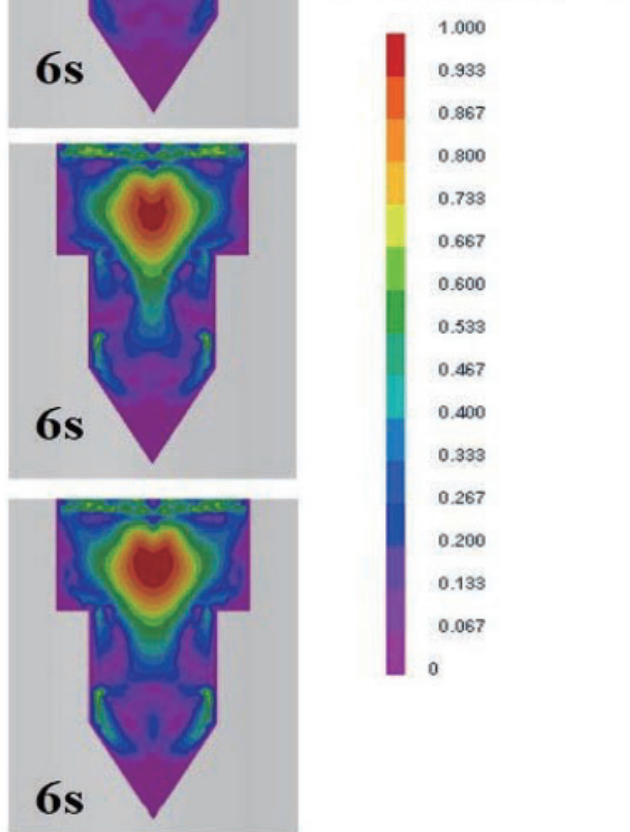

(a) Constant pressure of $0.1 \mathrm{MPa}(\# 1)$; (b) Constant pressure of $0.2 \mathrm{MPa}(\# 2)$; (c) Fluctuation pressure(\#3)

Fig. 6: Numerical simulation flow velocity of alloy melt during solidification under different conditions

(a)
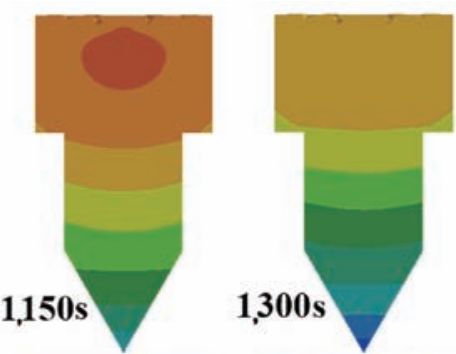

(b)
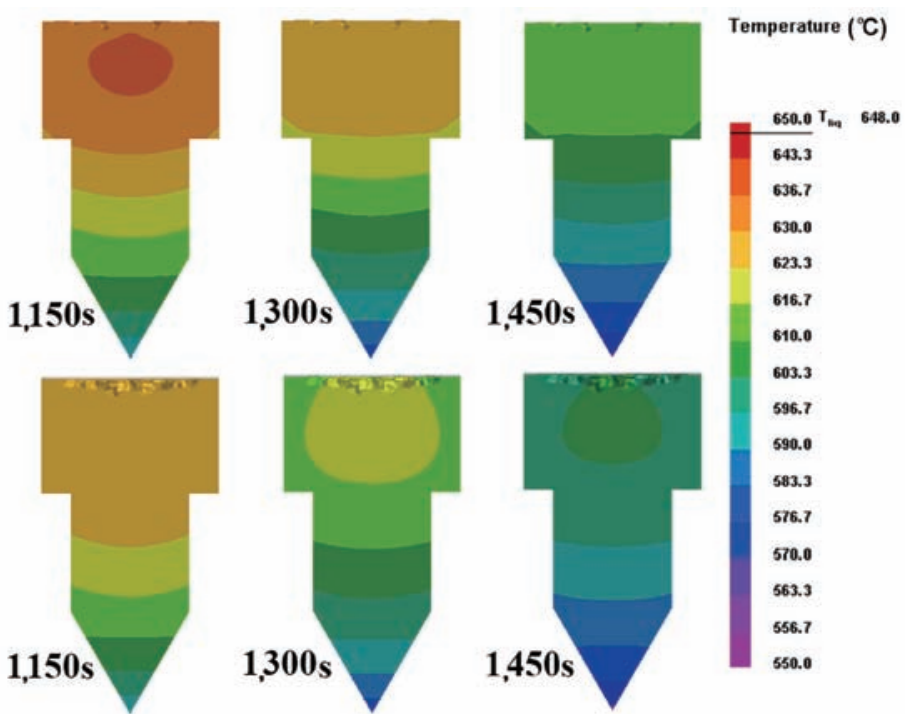

(c)
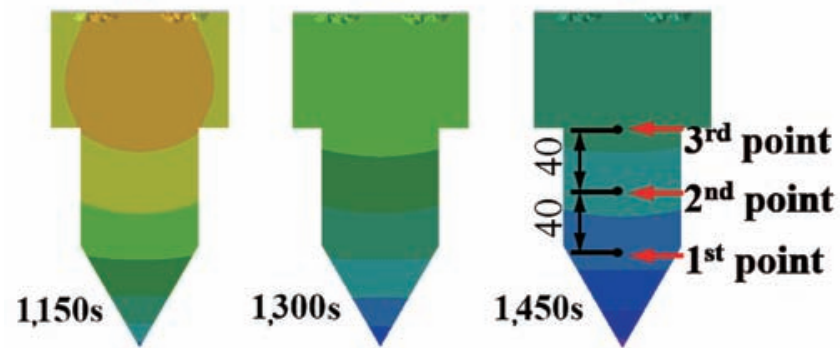

(a) Constant pressure of $0.1 \mathrm{MPa}(\# 1)$; (b) Constant pressure of $0.2 \mathrm{MPa}(\# 2)$; (c) Fluctuation pressure(\#3)

Fig. 7: Temperature fields of alloy melt during solidification under different conditions 
fluctuation pressure can form shrinkage porosities since there are closed temperature zones during the solidification process of the castings. The temperature fields under the three solidification processes show that the volume of the shrinkage cavity in the top of the riser increases with the increment of the applied pressure. This means that the applied pressure to the alloy melt can improve the feeding capacity of the riser. The casting with fluctuation pressure solidifies faster than the other two. The ultimate solidification part of the casting with fluctuation pressure moves to the riser and consequently the shrinkage porosity in the casting becomes less. The solidification curves of the castings under different solidification conditions are shown in Fig. 8. From the curve we can recognize that the solidification time of the castings is $1,800 \mathrm{~s}$, and there is sufficient time for the alloy melt to complete the feeding process. During this period, the constant pressure and the fluctuation pressure can all be applied on the alloy melt to promote the feeding process,

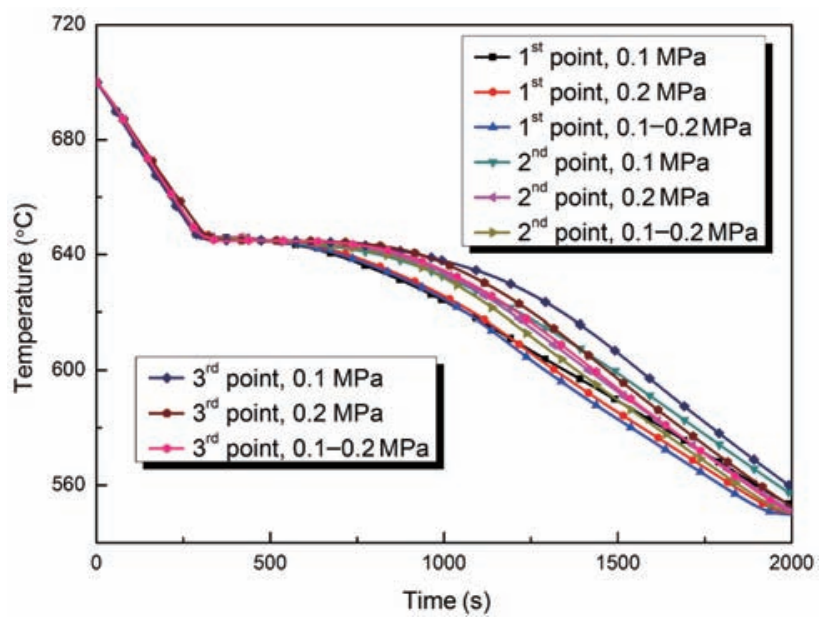

Fig. 8: Solidification curves of castings under different solidification conditions

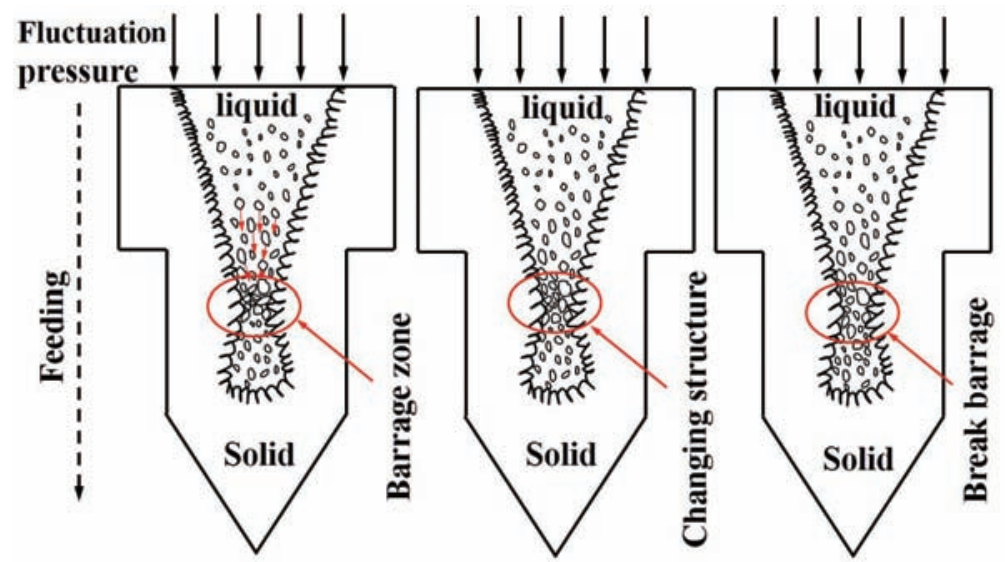

Fig. 9: Improvement of feeding capacity by fluctuation pressure improving the casting quality.

The reason for the improvement of the feeding capacity with vibration can be illustrated by Fig. 9. It is generally accepted that there are two necessary conditions to improve the feeding capacity of the alloy: one is that there must be sufficient and effective feeding pressure, and the other is that the alloy in the feeding channel must be flowing fluid. The two conditions are indispensable. There have been many studies on the feeding pressure and it will not be discussed in the present paper. However, it needs to be discussed on how the feeding channels change during the solidification process.

The fluctuation gas pressure applied on the molten metal surface can be seen as a vibration resource to the melt. The vibration can propagate in the whole solidified area of the casting, in which the structure created by solidified grains will be destroyed, finally resulting in the feeding channel change. The change plays a role in dredging the feeding channels in the solidification process, and thus improving the feeding capacity, as shown in Fig. 9. This result was also observed in our other experiment ${ }^{[25]}$

\section{Conclusion}

It is a very effective method to apply the fluctuation pressure to the top of the riser during the solidification process of ZL205A alloy to eliminate shrinkage porosity in the castings due to the fact that pressure fluctuation could induce vibration of the melt, while the vibration could increase the convection velocity of melt, change the solidification zone structure, delay the feeding channel closure, and finally lead to the casting feeding capacity improvement.

\section{References}

[1] Baoguang Sang. Numerical simulation and experimental study of inclusions and macrosegregation in the bottom-filled heavy steel ingots. Ph.D. Dissertation, Institute of Metal Research, Chinese Academy of Sciences, China, 2010.

[2] Wang J Q, Fu P X, Liu H W, et al. Shrinkage porosity criteria and optimized design of a 100-ton $30 \mathrm{Cr} 2 \mathrm{Ni4MoV}$ forging ingot. Materials \& Design, 2012, 35: 446-456.

[3] Hardin R A, Beckermann C. Prediction of the Fatigue Life of Cast Steel Containing Shrinkage Porosity. Metallurgical \& Materials Transactions A, 2009, 40(3): 581

[4] Li B, Shen Y, Hu W. Casting defects induced fatigue damage in aircraft frames of ZL205A aluminum alloy - A failure analysis. Materials \& Design, 2011, 32(5): 2570-2582.

[5] Buffière J Y, Savelli S, Jouneau P H, et al. Experimental study of porosity and its relation to fatigue mechanisms of model Al-Si7$\mathrm{Mg} 0.3$ cast Al alloys. Materials Science and Engineering: A, 2001, 316 (1-2): 115-126.

[6] Lados D A, Apelian D. Fatigue crack growth characteristics in cast $\mathrm{Al}-\mathrm{Si}-\mathrm{Mg}$ alloys: part I. Effects of processing conditions and 
microstructure. Materials Science and Engineering: A, 2004, 385: 200-211.

[7] Linder J, Axelsson M, Nilsson $\mathrm{H}$. The influence of porosity on the fatigue life for sand and permanent mould cast aluminum. International Journal of Fatigue, 2006, 28 (12): 1752-1758.

[8] Wang Q G, Apelian D, Lados D A. Fatigue behavior of A356/357 aluminum cast alloys. Part I: Effect of casting defects. Journal of Light Metals, 2001, 1(1): 73-84.

[9] You D D, Shao M, Li Y Y, et al. Numerical simulation of moldtemperature-control solidification. Transactions of Nonferrous Metals Society of China, 2007, 17 (3): 443-448.

[10] Mitrasinovic A, Hernández F C R, Djurdjevic M , et al. On-line prediction of the melt hydrogen and casting porosity level in 319 aluminum alloy using thermal analysis. Materials Science and Engineering: A, 2006, 428(1-2): 41-46.

[11] Sun $Y$, Luo J, Mi G F, et al. Numerical simulation and defect elimination in the casting of truck rear axle using a nodular cast iron. Materials \& Design, 2011, 32(3): 1623-1629.

[12] Verran G O, Rui P K M, Rossi M A. Influence of injection parameters on defects formation in die casting Al12Si1.3Cu alloy: Experimental results and numeric simulation. Journal of Materials Processing Technology, 2006, 179(1-3):190-195.

[13] Maltais A, Fiset M, Dubé D. An apparatus to grain refine metals and alloys with mold vibrations. Review of Scientific Instruments, 2005, 76(10): 647-129.

[14] Campbell J. Effects of vibration during solidification. Metallurgical Reviews, 1981, 26(1): 71-108.

[15] Chen R R, Zheng D S, Guo J J, et al. A novel method for grain refinement and microstructure modification in TiAl alloy by ultrasonic vibration. Materials Science abd Engineering: A, 2016, 653: 23-26.

[16] Gao X Q, Deng C, Xu J, et al. Effect of melt vibration on structure and mechanical properties of $\mathrm{HDPE} /$ nano- $\mathrm{CaCO}_{3}$ blend. Polymer Bulletin, 2010, 65(1): 59-68.

[17] Fu H Z, Shen J, Liu L, et al. Electromagnetic shaping and solidification control of $\mathrm{Ni}$-base superalloys under vacuum. Journal of Materials Processing Technology, 2004, 148(1): 2529.

[18] Ganapathysubramanian B, Zabaras N. On the control of solidification using magnetic fields and magnetic field gradients. International Journal of Heat and Mass Transfer, 2005, 48(19-20):4174-4189.

[19] Chen Bangfeng, Jia Panjiang. Application of ZL205A High Strength and High-quality Casting in Large Aircraft. Journal of Materials Engineering, 2009, 30(1): 77-80. (In Chinese)

[20] Zhang Ming, Zhang Weiwen, Zhao Haidong, et al. Effect of pressure on microstructures and mechanical properties of AlCu-based alloy prepared by squeeze casting. Transactions of Nonferrous Metals Society of China, 2007, 17(3): 496-501.

[21] Li M, Wang $H$, Wei $Z$, et al. The effect of $Y$ on the hot-tearing resistance of Al-5wt.\%Cu based alloy. Materials \& Design, 2010, 31(5): 2483-2487.

[22] Feng Z J, Shen Z J. Low Pressure Casting of Large Aluminum Alloy Castings. Foundry, 2003, 52(12): 1186-1188. (In Chinese)

[23] Campbell J. Castings. 2nd ed. Oxford: Butterworth, 2003: 212218.

[24] Nagira T, Nakatsuka N, Yasuda H, et al. Impact of melt convection induced by ultrasonic wave on dendrite growth in Sn-Bi alloys. Materials Letters, 2015, 150: 135-138.

[25] Wang Rujia, Wu Shiping, Chen Wei. Mechanism of burst feeding in ZL205A casting under mechanical vibration and lowpressure. Transactions of Nonferrous Metals Society of China, 2018, 28 (2): 319-325.

This work was financially supported by the National Natural Science Foundation of China (No. 51475120) and the Joint Fund of Research of Advanced Manufacturing Technology in Aerospace (No. U1537201) 